\title{
A Design and Development of micro-Learning Content in e-Learning System
}

\author{
Yasung Park ${ }^{\#}$, Yong Kim ${ }^{\#}$ \\ ${ }^{\#}$ Department of e-Learning, Graduate School, Korea National Open University, Seoul, 03087, Korea \\ E-mail: yasman79@naver.com,dragonknou@gmail.com
}

\begin{abstract}
In the rapidly changing digital era, changes in learning through e-learning are required. Micro-learning contents were analyzed as a method that can replace the e-learning contents in existing regular courses implemented with large amounts of learning and large contents. In the present study, a method for easy and quick production of contents was presented for effective microlearning services. The results of the study indicated that the micro-learning content development method presented in the present study is valid in terms of the efficiency of content development. The content development method presented in the present study is considered to bring about new changes to the existing e-learning content development methods utilizing flash, HTML5, H5P, etc.
\end{abstract}

Keywords - e-learning; micro-learning; content; e-learning system; H5P

\section{INTRODUCTION}

Job holders that do both learning and work feel burdens in learning through e-learning in regular courses that leads to the consumption of relatively large amount of physical time and money because following the e-learning in regular courses in short times in daily living is somewhat difficult as the flows of learning is broken or the contents are too long to understand at once in the short times. Consequently, online lecture drop rates exceeded $50 \%$ and there have been many cases where learners could not complete the course despite that they had high levels of will and passion for learning or failed to achieve the purpose of learning [1], [2].

In addition, due to the rapid changes in knowledge and technology, and the quantitative growth of media exposure, the existing e-learning content development method that develops contents over long periods of time revealed limitations for timely learning. Methods that can solve such problems in e-learning contents and changes in existing contents development methods through new media were necessary [3], [4]. In the present study, micro-learning was presented as an alternative that can solve the problems in the existing e-learning contents in regular courses, methods that can efficiently develop micro-learning contents were examined, and those methods were compared and analyzed with the existing e-learning contents to propose a content development method suitable for the implementation of micro-learning contents for e-learning and verify the validity.

\section{MATERIAL AND METHOD}

\section{A. Micro-Learning}

Micro-learning is defined as independent contents that have concrete single themes while being composed of small units and can be learned at once through simple interactions and learning activities through those contents [5], [6]. Microlearning can serve personalized learning and on-demand selective learning, helping learners to acquire new knowledge and remedy omissions in their existing knowledge [7]. Micro-learning can also reflect the learner's consciousness and habituation for learning instead of strong intentionality and motivation [8]. The characteristics of micro-learning include the fact that it enables interactions with small learning units and combinations of short contents so that the cognitive loads for the information provided for learning [9]-[11]. Micro-learning also enables finding related data, photos, and videos in mobile environments in real time, so that the time required to find certain themes and contents can be shortened. Micro-learning is provided in the webbased environment as well as the mobile environment. Mobile learning and micro-learning can be used together for the development of short online activities in e-learning [12].

Micro-learning is classified by the types of learning objects and when developing its contents, the level of difficulties in the production of content authoring tools that are a technical element of content development methods should be lowered, and distribution and the utilization of 
outputs should be improved [13], [14]. These common characteristics are as follows.

TABLE I

COMMON CHARACTERISTICS REQUIRED FOR THE DEVELOPMENT OF MICRO-LEARNING CONTENTS

\begin{tabular}{|l|l|}
\hline \multicolumn{1}{|c|}{ Item } & \multicolumn{1}{|c|}{ Characteristics } \\
\hline Adequacy & $\begin{array}{l}\text { The level of difficulty that enables the } \\
\text { generation and updating of contents without IT } \\
\text { experts }\end{array}$ \\
\hline Convenience & $\begin{array}{l}\text { Web-based contents linked to the authoring tool } \\
\text { can be made and revised }\end{array}$ \\
\hline Efficiency & Short time required for production \\
\hline Usability & $\begin{array}{l}\text { The openness and simplicity of the form of } \\
\text { distribution and outputs through the web }\end{array}$ \\
\hline Recency & $\begin{array}{l}\text { Newest technologies can be applied such as } \\
\text { support for mobile devices }\end{array}$ \\
\hline
\end{tabular}

In case of developing micro-learning contents, there are considerations. In order to apply some of the micro-learning contents to existing regular curriculum as learning objects and replace regular curriculum with micro-learning, there are four considerations according to learning development strategies as shown in Table 2. Based on them the curriculum can be composed [14], [15].

TABLE II

CONSIDERATIONS IN DEVELOPING MICRO-LEARNING CONTENTS

\begin{tabular}{|c|l|}
\hline Elements & \multicolumn{1}{|c|}{ Contents } \\
\hline Assessment & $\begin{array}{l}\text { Defining the object of change using the } \\
\text { requirements of organization and micro- } \\
\text { learning }\end{array}$ \\
\hline Evaluation & $\begin{array}{l}\text { Investigating about low participation and its } \\
\text { causes among regular curriculum }\end{array}$ \\
\hline Mapping & $\begin{array}{l}\text { Composing appropriate instructional designs } \\
\text { among various subjects and methodologies }\end{array}$ \\
\hline Definition & $\begin{array}{l}\text { Defining accurately budget, duration, and } \\
\text { internal resources }\end{array}$ \\
\hline
\end{tabular}

First, the level of target subject should be defined and used through requirements which are necessary for curriculum with assessment element such as pre-diagnosis. Especially it is necessary to define specific objects. Thus, it also should be decided what the requirements of the company which conducts training and who should be a target of change by using micro-learning.

Second, the micro-learning can be applied to investigate learning time and learning amount by analysing causes of low participation in the regular curriculum. Especially in the field of lifelong e-learning, the reason for learner-led dropout is a learning schedule which does not consider the amount of learning and personal life [16]. Whether it is appropriate to provide a small unit of contents with learning cycle within designated period or not should be confirmed. In other words, it should be checked whether micro-learning is a right choice to solve problems such as low rate of participation.

Third, it is necessary to choose types of learning objects according to the theme and contents of the curriculum. One learning goal or theme per learning object of microlearning should be assigned and used. It is also necessary to suggest learning goal, learning and evaluation together as a single learning object.

Finally, the budget, duration, and internal resources should be clearly defined. Thus, advantages of microlearning such as low budget, time savings, and recycling of resources should be fully utilized for comparing and examining ongoing plans of the curriculum.

\section{B. Contents Development Methods and Development Case Analysis}

The micro-learning content development method mainly developed components according to clear purposes for the single theme of the learning object and could concretize learning strategies that fit the flow of learning. In order to achieve an effective learning process, micro-learning contents also needed to be presented in accordance with the context of a learner [17]. When the method for development of the types of learning objects which are the smallest learning units defined in micro-learning was analyzed, it could be seen that most offline based authoring tools did not provide functions that correspond to system linkage. Online based authoring tools did not provide functions for interactions or any dashboard for performance presentation, and since H5P was the only authoring tool implemented based on platforms, H5P was proposed as a software solution for the development of micro-learning contents. Overseas cases and domestic informal earning cases were analyzed based on a clear purpose and understanding microlearning, and the following results were obtained [3]. First, micro-learning contents mainly composed of time learning, experiments and practices, and simulations considering field practices in the area of lifelong education were lacking. Second, the composition ratio of contents for higher education courses was high, and most courses were composed by subject. Third, the contents were designed with mobile first strategies for fast learning. Fourth, the ratio of design and development strategies through interactions was low in areas of expertise. Finally, the contents were connected to metadata so that the contents can be searched with similar meanings or correlations.

\section{RESULT AND DISCUSSION}

\section{A. Needs Analysis and Design}

Through implications of previous studies, design and development had to be conducted through the following development procedures differentiated from existing cases. First, learners and previous operating processes should be analyzed, and the results should be reflected in the selection of processes and goal setting. Second, stages that are not required by learners should not be included in the design and structuralized. Third, technical methods of content development should be simplified and universalized so that they can be provided for utilization.

Learners' requirements were analyzed to select processes and processes utilizing scanning electron microscopes were selected for technology and engineering areas reflecting the fact that education on expensive equipment is required. The contents were composed of a total of four sessions not exceeding 15 minutes per session so that understanding of theories, and equipment operation and analysis ability can be 
cultivated. Learning in smaller contents has support for learning psychology and short-term memory literature [18], [19].

Basic design and development strategies were composed into one learning unit based on interactive videos, and the learning flow chart was set to comprise introduction, learning, and finalizing stages. As a prior learning preparation stage, in the introduction, checkboxes were presented to help the acquisition, understanding of knowledge necessary for practices on equipment. In this learning process, explanations through videos and sudden quizzes were presented together as an interactive device to test explained contents. In the finalizing stage, evaluation questions were flexibly selected and applied based on the contents of the theory of practice of the implemented learning object. Whether the design characteristics of microlearning contents were reflected on the contents is set forth in Table 3.

TABLE II

DESIGN CONTENT ITEMS FOR THE DESIGN CHARACTERISTICS OF MICROLEARNING CONTENTS

\begin{tabular}{|c|l|}
\hline Item & $\begin{array}{c}\text { Contents that Match with the Learning } \\
\text { Object of the Selected Course }\end{array}$ \\
\hline Single theme & $\begin{array}{l}\text { Introduction of sample pre-treatment processes } \\
\text { which are part of analysis procedure } \\
\text { Short interactive video not exceeding 10 } \\
\text { minutes } \\
\text { Metadata } \\
\text { Tags registered based on those keywords of } \\
\text { which the information can be searched } \\
\text { Utilized images are implemented as learning } \\
\text { objects and create web addresses } \\
\text { Present the utilization of the contents on large } \\
\text { equipment as videos } \\
\text { Resource sharing can be developed as H5P } \\
\text { Contents to enable sharing through the web } \\
\text { and reproduction }\end{array}$ \\
Resource \\
sharing
\end{tabular}

\section{B. Contents Development}

The plug-in function was added to the web editor of Learning Contents Management System (LCMS). The learning content management system makes such functions possible as production, distribution, revision, and management of online contents for developing microlearning contents. The authoring tool of H5P which can be used as content authoring tool is applied. Drupal, Wordpress, and Moodle also provide H5P plug-in. The Wordpress is selected because the Wordpress is easy to modify through application programs and can change file structure. It also does not require many times and effort for customizing. The Wordpress is comparatively simple and universal.

Bitnami Wordpress and H5P plug-in are installed for providing a domain service on the web address and connecting and operating mobile. Bitnami Wordpress and $\mathrm{H} 5 \mathrm{P}$ are accessible with official IP from outside and include a web server within MS Window 7. With them, the authoring tool which can develop online based contents is constructed [20].

The computer with CPU 3.4GHz and RAM 4.0GB is used for developing prototype contents of micro-learning, and standard software is based on the environment of MS Window 7. The specification is shown in Table 4.
TABLE IV

SOFTWARE AND HARDWARE ENVIRONMENT

\begin{tabular}{|l|l|l|}
\hline Environment & Classification & \multicolumn{1}{|c|}{ Specification } \\
\hline \multirow{4}{*}{ Software } & OS & MS Windows7 enterprise \\
\cline { 2 - 3 } & Web browser & $\begin{array}{l}\text { Chrome, Firefox, Internet } \\
\text { Explorer }\end{array}$ \\
\cline { 2 - 3 } & Language & $\begin{array}{l}\text { Html, PHP, Javascript, } \\
\text { CSS, SCSS, JSON }\end{array}$ \\
\cline { 2 - 3 } & Web server & $3.4 \mathrm{GHz}$ \\
\hline \multirow{2}{*}{ Hardware } & CPU & $4.0 \mathrm{~GB}$ \\
\cline { 2 - 3 } & RAM &
\end{tabular}

The process of making learning objects about interactive video consists of uploading video, adding interactive and inputting summary quizzes.

The first step is preparation. In this step, motivation video and interview video are suggested, and a guideline for learning goal is also provided. Gamification or demonstration for application is suggested, and short quizzes with adding interaction are included in the 2 nd step. The final step is an organizing and summary step which provides quizzes, outcome board and a summary. These three steps are shown in Table 5.

TABLE V

DEVELOPING STEPS OF MICRO-LEARNING CONTENTS

\begin{tabular}{|c|l|}
\hline Steps & \multicolumn{1}{|c|}{$\begin{array}{c}\text { Learning Elements of micro-Learning } \\
\text { Contents }\end{array}$} \\
\hline $\begin{array}{c}\text { Intro } \\
\text { (Uploading } \\
\text { video) }\end{array}$ & $\begin{array}{l}\text { video for learning motivation, interview } \\
\text { video, pre-diagnose quiz }\end{array}$ \\
\hline $\begin{array}{c}\text { Learning } \\
\text { (Adding } \\
\text { interaction) }\end{array}$ & $\begin{array}{l}\text { gamification, interaction video, a } \\
\text { demonstration for application, quiz }\end{array}$ \\
\hline $\begin{array}{c}\text { Organizing } \\
\text { (Organizing \& } \\
\text { summary) }\end{array}$ & suggesting outcome board, summary, quiz \\
\hline
\end{tabular}

In the first step of uploading video and embedding video, the video clip of explaining learning contents is uploaded, action bar, frame and phrases and languages for quiz feedback are modified. The title of a relevant learning object is suggested with the playing of contents. The title is also inserted in the input form for using them in steps of summary and screen of learning results. The basic copyright, for example, sources and information about video and contents are listed. Poster images of video which are registered as MP4 file are registered. The screenshot of developing contents in the 1st step is shown on Fig. 1.

In the 2nd step of adding interaction experimental instrument which is used for learning and comparing methods, movement animation is suggested with video by adding defined interaction types. The prototype which reflects a design strategy of micro-learning is about an electron microscope. Since the subject is about the explanation of the theory of electron microscope and the process of dealing objects, these subjects are developed according to a module. The interaction with a small module is composed by a pop-up screen according to a user input event for inducing easy application of users. Thus learner can select learning elements and pay more attention to them. 


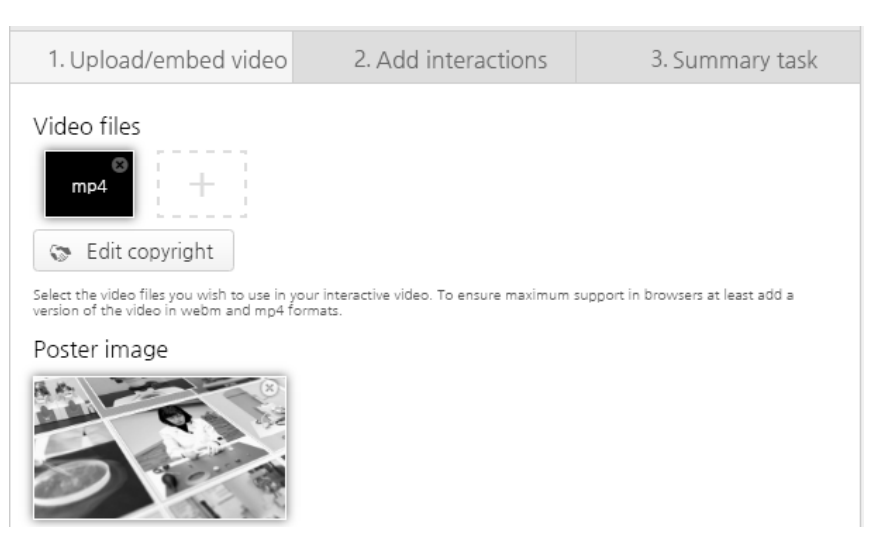

Fig. 1 The screenshot of developing contents in the step of uploading video

In the section of suggesting keywords bold subtitles are synchronized with the video for controlling attention of learners and screen design for emphasizing text or image effect is included in order to recognize the aural keyword as a visual one. The contents which are not included in the screen are put in the type of animated GIF and text pop-up.

Each keyword is added to the bookmark in order that the section of video with keywords of the lecture can be searched. The menu of a bookmark or a bookmark of each video section is marked.

The final step of organizing and summarizing is decided by suggesting the contents of the theory and developed selectively. The questions which can be shared with other evaluations are suggested in the type of quizzes, and the type of multiple choices with description are suggested.

\section{Development and Process Evaluation}

To develop micro-learning contents, which are the purpose of the present study, an H5P authoring tool that can be utilized as a contents authoring tool as the plugin function was added to a contents management system that can implement online, all functions of contents writing, distribution, and management was applied to the test environment. Thereafter, an environment necessary for development was prepared by setting the system, localizing the language, and customizing the style sheet, etc. Whether the contents were developed to satisfy the points for improvements of development processes was checked through Table 6.

TABLE VI

CHECKLIST FOR THE REFLECTION OF POINTS FOR IMPROVEMENTS OF CONTENTS DESIGN AND DEVELOPMENT

\begin{tabular}{|l|c|}
\hline \multicolumn{1}{|c|}{ Items to be Checked } & \multicolumn{1}{|c|}{$\begin{array}{l}\text { Whether } \\
\text { Reflected }\end{array}$} \\
\hline $\begin{array}{l}\text { Were 3 4 learning object units combined } \\
\text { to compose one session? }\end{array}$ & \multicolumn{2}{|c|}{$\sqrt{ }$} \\
\hline $\begin{array}{l}\text { Were those lifelong learning courses for } \\
\text { expert skill areas that are required in } \\
\text { industrial fields designed? }\end{array}$ & \multicolumn{2}{|c|}{} \\
\hline $\begin{array}{l}\text { Was the curriculum composed reflecting } \\
\text { the ability unit elements for knowledge } \\
\text { and job skills? }\end{array}$ & $\sqrt{\mid}$ \\
\hline $\begin{array}{l}\text { Were knowledge, understanding and } \\
\text { procedures/methods presented? }\end{array}$ & \multicolumn{2}{|c|}{} \\
\hline
\end{tabular}

Were demo videos or interactions for $\quad \sqrt{ }$

equipment practice utilized?

The results of analysis of micro-learning content model courses through comparison with e-learning contents are as follows. First, the contents' history is managed through prior diagnosis, and results of learning after sudden quizzes to secure linkage with the stage of evaluation. Second, since subtitle editing and interactions are not required in the image editing or program stage by existing e-learning workers, budgets and production time are saved. Third, since the contents are not managed by file by a separate source, the relevant contents can be easily reconstructed, and stages up to the reproduction through reconstruction were simplified. Fourth, since maintenance following errors and demands for updates is performed in a lump through the contents management system, the existing stage relying on contents development service providers or contents developers can be removed. These analysis results are compared and arranged to match the analysis, development, and design stages in general processes of e-learning content development in Table 7.

TABLE VII

THE PROCESS OF DEVELOPMENT OF THE MICRO-LEARNING CONTENTS APPLIED TO THE MODEL COURSE

\begin{tabular}{|l|c|}
\hline Division Stage & \multicolumn{2}{|c|}{ Development Process } \\
\hline Analysis & $\checkmark$ requirements of organization and \\
& $\checkmark$ individuals \\
& $\checkmark$ definition/analysis / design of the target of \\
Design & $\checkmark$ change \\
Development & $\checkmark$ preparation of teaching plan and \\
& $\checkmark$ development, contents interface \\
& $\checkmark \begin{array}{l}\text { design(teacher) } \\
\text { multimedia production(teacher / content } \\
\end{array}$ \\
& \multicolumn{2}{c|}{ developer) } \\
\hline
\end{tabular}

The changed development process brought about improvement in production quality even with limited inputs of e-learning workers unlike the case of development of regular courses where contents are developed only when the requirements of teachers that are experts in contents, teaching designers, content developers, the image taking and system developers have been satisfied. In fact, the production of micro-learning contents required less participation of e-learning workers, and it was identified that the most effective production could be achieved with the input of smaller numbers of workers.

\section{Feasibility Verification}

To verify the feasibility of micro-learning content development through open source based content development authoring tools, experts working in the related area were selected as study participants, and the feasibility was verified through interviews.

The content of the interview is about comparing existing developing the methods and convenience and satisfaction of developing method which is a development plan for microlearning contents. Terms about micro-learning are fully explained and understood by interviewees in case of having a one-to-one interview. The interviewees use development 
system of micro-learning by creating an account. Their opinions are also collected by interview and practices.

The evaluation index for validity verification reflects evaluation standards of quality control on e-learning contents, components of e-learning and common features of micro-learning which are results of preceding researches. However, the prioritized elements of developer which are considered in the phase of content development are compared and selected among components of content. Since this is the evaluation about software solutions of technical methods, design strategy and ethicality are excluded [21], [6], [22].

The evaluation items which are collected by priority of developers are the technical stability of the program, the relevance of interface, interaction, the convenience of installing and running programs, the relevance of supporting the upgrade, quality responsibility and expense analysis. The theme is selected by the relevance of difficulty and relevance of supporting update which is required in developing micro learning contents. There are 5 areas of verification contents. The interview subjects are as followings; relevant with a level of application difficulty, the convenience of modification and production, the effectiveness of production time, utilization of distribution and print type and technical update of supporting mobile devices. The participants in the research mark evaluation score of each theme from 1 to 10 . The theme of the interviews is as follows.

TABLE VIII

THEME OF INTERVIEW

\begin{tabular}{|l|c|}
\hline \multicolumn{1}{|c|}{ Theme } & Evaluation Index \\
\hline $\begin{array}{l}\text { Marking evaluation score on level of } \\
\text { production difficulty and giving opinions }\end{array}$ & Relevance \\
\hline $\begin{array}{l}\text { Marking evaluation score on } \\
\text { modification based on Web environment } \\
\text { and convenience of producing and giving } \\
\text { opinions }\end{array}$ & Convenience \\
\hline $\begin{array}{l}\text { Marking evaluation score on production } \\
\text { lead time and giving opinions }\end{array}$ & Effectiveness \\
\hline $\begin{array}{l}\text { Marking evaluation score on satisfaction } \\
\text { of distribution and giving opinions }\end{array}$ & Utilization \\
\hline $\begin{array}{l}\text { Marking evaluation score on reflecting } \\
\text { updated technology for supporting } \\
\text { mobile devices and giving opinions }\end{array}$ & Update \\
\hline
\end{tabular}

First, the average score of 'relevance' is 6.0 points. According to research participants, it is not necessary to make complex coding by themselves. There is a difference in the level of difficulty per function of the template, but it is easy to develop contents by clicking. A research participant who gives lowest score 3 is facing difficulty at first due to the unfamiliarity of developing method, but since there are similar development environments to existing authoring tool of e-learning contents, it was easy to use. If users fully understand the manual of content development, it is much faster than existing development method of e-learning contents.

Second, the average score of 'convenience' is 7.2 points. Although there is not enough time to understand about the usage, the satisfaction on convenience is high. According to other's opinion, there is no difference between uploading speed of distance and on-site production, and there is no resistance because of accustomed environments of development. Since it can be stored in web and edited, cooperative works or development works of group unit which cannot be executed by other developing methods are possible. They correspond to cooperation and speedy production, which are goals of online-based authoring tools.

Third, the average score of 'effectiveness' is 7.0 points. Since in existing e-learning contents HTML based contents and Flash-based multimedia contents have fragmented tasks by step, it is easy to manage effectively. It is because there are fewer steps from production to reviewing. There is an opinion that since participant is not familiar with the provided content development system, the participant cannot decide whether it is appropriate or not. However, the development time is saved by repeated works, and it is easy to proceed. It is expected that unnecessary roles of e-learning content developer are reduced, and the development cost will reduce in case of development of micro-learning contents.

Forth, the average score of 'utilization' is 7.2 points. The participants satisfy this evaluation index. Reducing waiting time for the final outcome after developing contents is required by participants.

Fifth, the average score of 'update' is 7.7 points. The result of the interview shows that since the contents are connected to mobile devices in real time, the participation rate increases. The inconvenience of existing e-learning contents such as transforming them for mobile environments will be solved, according to participants.

In summary, when we compare the development system for micro-learning contents with existing writing tools of elearning contents, we are facing difficulties in new development environments. However, most of the research participants say that repeated studies with the manual help to accustomed to it. Since it is the online based production tool, it is easy to produce and modify in the web and reduce production time. In addition, it reflects such web features as free distributing and printing. Since it supports advanced technology of mobile learning, it can provide teacher customized learning environments regardless of time and place.

The Fig. 2 visualizes average scores of evaluation. The polygonal diagram clearly shows that which evaluation index is more specialized. As shown on the diagram in terms of a technical update, print type and production time is specialized. The average score of five evaluation indexes is 7.0 points. It is comparatively appropriate that the developing authoring tool and developing methods of microlearning content with $\mathrm{H} 5 \mathrm{P}$ which is suggested in this study.

\section{CONCLUSION}

In the present study, a micro-learning content development method was studied to replace existing of elearning and provide customized contents considering the learners' learning time and environments. To this end, specialized web-based authoring tools were necessary as well as a platform that enables easy writing from the viewpoint of teachers and enables searching for and learning about short micro-learning contents, utilizing as learning 
data. To apply micro-learning contents, the following points for improvement should be considered by stage of development and management processes.

First, when a course is planned, improvement of points of failure in the existing regular courses and subjects that require changes in learning should be analyzed. Second, when the contents are designed, stages not necessary for learning should not be included in the theoretical design. Third, the diverse and complicated technologies such as interface design and multimedia that is in the area of content developers should be simplified to the extent that teachers can develop contents utilizing the tools. Fourth, you can consider LCMS to manage micro-learning contents. These days, systems are considered management based on clouding computing for effective management [23]. Therefore, clouding computing should consider applying LMS or LCMS for micro-learning.

Based on the present study, future changes from elearning to micro-learning will change content development methods to be more practical.

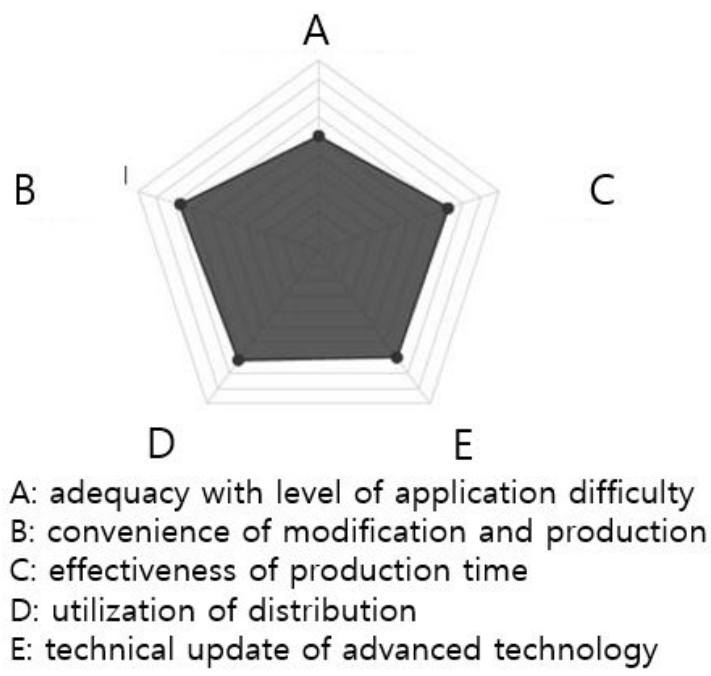

Fig. 2 Validity of H5P evaluation index

\section{REFERENCES}

[1] T. Hug, "Micro-learning and narration," in Proc. MiT4'05, pp. 6-8, 2005.

[2] K. S. Bae, "The Reasons for Attrition of the adult students participating in Vocational Education and Training," M. Edu. Thesis, Korea University of Technology and Education, 2004.
[3] S. Y. Yi, "A Study on The Way of Informal Learning at Corporate Workplace," The Korean Journal for Human Resource Development, vol. 11, pp. 1-51, 2009.

[4] T. Hug, Didactics of microlearning: Concepts, Discourses and Examples, ed., Munster, Germany: Waxmann-Verlag, 2007.

[5] G. Gerhard, T. Hug, and C. Glahn, "Integrated Micro learning - An outline of the basic method and first results," in Proc. ICL'04, 2004, p. 109-121.

[6] M. L. Ahn, K. A. Son, and Y. Kim, "Development of Quality Assurance Guidelines for e-Learning Contents," Journal of Educational Technology, vol. 22, pp.171-193, 2006.

[7] W. Chuanxue and J. Zhang. "Design of a microlecture mobile learning system based on smartphone and web platforms," IEEE Transactions on Education, vol. 58, pp. 203-207, 2015.

[8] D. Zhitao, "Factors Influencing the Behavior of Network "MicroLearning" Participants: Empirical Analysis Based on Structural Equation Model," Journal of Intelligence, vol. 36, pp.173-181, Jan. 2017.

[9] P. A. Bruck, L. Motiwalla and F. Foerster, "Mobile learning with micro-content: a framework and evaluation," in Proc. BLED'12, 2012.

[10] T. Hug, M. Lindner, and P. A. Bruck, "Microlearning: Emerging concepts, practices and technologies after e-learning," in Proc. Microlearning'05, 2005, paper.

[11] L. P. A. Simons, and P.A. Luuk, "Microlearning mApp raises health competence: hybrid service design," Health and technology, vol. 5, pp. 35-43, Jun. 2015.

[12] D. Kamilali and C. Sofianopoulou, "Microlearning as Innovative Pedagogy for Mobile Learning in Moocs," ML'15, 2015, p. 127-131.

[13] H. J. So and H. R. Lee, "Analysis and Implications of the Research Trend on Microlearning," Korea Science \& Art Forum, vol.30, pp.189-201, 2017.

[14] Allencomm, Microlearning Techiniques, Allencomm e-book, 2016.

[15] Don McIntosh, "Vendors of learning management and e-learning products", Learning Management Vendors, pp.88-96, 2014.

[16] K. S. Bae, "The Reasons for Attrition of the adult students participating in Vocational Education and Training", Master's thesis, Korea University of Technology and Education, 2004.

[17] K. Kuwabara and B. Roengsamut, "Content Co-creation and Refinement for Microlearning Settings," eLmL'15, 2015, p. 44-47.

[18] H. A. Simon, "How big is a chunk?," Science, vol. 183, pp. 482-488, Feb. 1974.

[19] N. Cowan, "The magical number 4 in short-term memory: A reconsideration of mental storage capacity," Behavioral and Brain Sciences, vol. 20, pp. 87-114, Feb. 2001.

[20] G. Alexis, Html5 \& CSS3 for the Real World, Oreilly \& Associates, 2015.

[21] M. H. Kang, H. I. Nam, H. S. Choi, and M. Y. Kim, "Identifying the Core Criteria on E-learning Contents Quality Assurance", Journal of Employment and Skills Development, vol.12 No.2, pp. 195-218, 2009.

[22] E. J. Ahn, "A study on the learner's satisfaction with e-learning contents by different types of visual presentations", Master's thesis, Hongik University, 2009.

[23] A. M. Kadhum and M. K. Hasan, "Assessing the Determinants of Cloud Computing Services for Utilizing Health Information Systems: A Case Study", International Journal on Advanced Science, Engineering and Information Technology, Vol. 7 No. 2, pp.503-510, 2017. 